\title{
Las primeras formas del Indigenismo en Argentina: la voz de sus precursores
}

\author{
María del Carmen NiCOLÁs AlBA \\ mnicolaalba@email.arizona.edu \\ University of Arizona
}

\begin{abstract}
RESUMEN
Los discursos narrativos en busca de una identidad nacional que se fueron produciendo en Argentina después de la Organización Nacional coincidieron con la llegada masiva de inmigrantes y la finalización de la Conquista del Desierto, con la que se consiguió, si no exterminar, sí asimilar a miles de indígenas. Sin embargo, ante la excesiva cosmopolitización de Buenos Aires, surgieron voces que clamaban por una autenticación de la argentinidad. Ciertos escritores del interior que ya contaban con el beneplácito de la intelectualidad bonaerense comenzaron a publicar discursos nativistas como oposición a las nuevas tendencias extranjerizantes en un intento por la rehabilitación de una tradición nacional y en un espacio editorial menos competitivo, pero también como un retroceso al pasado bucólico que solo el interior del país podía representar. En este artículo se abordarán los discursos regionalistas que dieron voz a la realidad indígena que había sido olvidada como depositaria de la identidad nacional, como las obras de Joaquín V. González y de Ricardo Rojas. Estos discursos, junto a las indagaciones arqueológicas de Juan Bautista Ambrosetti, Lafone Quevedo y Adán Quiroga, contribuyeron a revalorizar el pasado indígena argentino y a renovar la imagen del indio quien, sin embargo, aún sufría la invisibilidad y la explotación, hechos que sí supo ver aisladamente Juana Manuela Gorriti en su cuento "Si haces mal no esperes bien" de 1860. Aunque la denuncia social en la literatura se produjo algunas décadas más tarde, las tendencias herderianas de principios de siglo sirvieron de acicate para un desarrollo posterior plenamente indigenista.
\end{abstract}

Palabras clave: Indigenismo, Juana Manuela Gorriti, Ricardo Rojas, Joaquín V. González.

\section{The forefathers of Indigenismo in Argentina}

\begin{abstract}
The narrative discourses looking for a national identity in Argentina after the period known as Organización Nacional were produced at the time of the massive arriving of immigrants and once finished the Conquest of the Desert, that achieved, if not the extermination, the assimilation of thousands of native peoples. However, in view of the excessive cosmopolitanization of Buenos Aires, there were some voices that clamored for an authentication of Argentineness. Some inland writers that already had the blessing of Buenos Aires intelligentsia started to publish nativist discourses as an opposition to the new foreign trends in an attempt to reinstate the national tradition in a less competitive editorial area, but also as a retreat to a bucolic past that could only be represented by the inlands. In this article, the regionalist discourses that gave a voice to the native reality that had been forgotten as the
\end{abstract}


holder of the national identity will be tackled, such as the works of. Joaquín V. González and Ricardo Rojas. These discourses, together with the archeological investigations of Juan Bautista Ambrosetti, Lafone Quevedo and Adán Quiroga contributed to reevaluate the Argentinian native past and to renovate the image of the Indian, who, however, suffered invisibility and exploitation. Juana Manuela Gorriti was the only one that was able to reflect these injustices in her tale "Si haces mal no esperes bien" in 1860. Even though the social denounce was produced a few decades later, the Herderian tendencies at the beginning of $20^{\text {th }}$ century served as an incentive for a fully indigenista development.

Keywords: Indigenismo, Juana Manuela Gorriti, Ricardo Rojas, Joaquín V. González.

Se conmueven del Inca las tumbas $\mathrm{Y}$ en sus huesos revive el ardor Lo que ve renovado a sus hijos De la Patria el antiguo esplendor

Estos cuatro versos del himno nacional argentino, que conciben como argentinos a los descendientes del Incario, añadiéndoles, además, cualidades humanas dignas de enorgullecer a todo un pueblo, fueron eliminados en 1900 por discrepar enormemente con el proyecto de colonización de Argentina, iniciado a mediados del siglo XIX con la Organización Nacional (1853-1880) cuya constitución fue inspirada por las Bases de Juan Bautista Alberdi. En esta obra, Alberdi reniega de la herencia precolombina de los americanos, desposee a los indígenas de un estatus civilizado dentro de la sociedad y rechaza su capacidad para poblar Argentina como una nación avanzada: "En América todo lo que no es europeo, es bárbaro; no hay más división que ésta: primero, el indígena, es decir, el salvaje; segundo, el europeo, es decir, nosotros, los que hemos nacido en América, y hablamos español, los que creemos en Jesucristo y no en Pillan (dios de los indígenas)". Al contrario, Alberdi confía en la regeneración de la nación a través de políticas migratorias que atraigan a los europeos, los únicos capaces de conseguir regenerar la vida pública y social: "La Europa nos traerá su espíritu nuevo, sus hábitos de industria, sus prácticas de civilización, en las inmigraciones que nos envíe” (1920: 76).

Tanto Alberdi como sus compañeros de la Generación del 37, caracterizados por una revitalización del Ideal de Mayo, insistieron en su antiespañolismo y en la oposición axiológica entre el indígena y el criollo. Así, en sus obras literarias, las figuras indígenas hacen su aparición envueltos por una áurea exótica que les desprovee de toda humanidad, señalando la civilización europea como el camino hacia el progreso.

Indudablemente, el pensador de la época que más influiría a las generaciones futuras - para ratificarlo o desmentirlo- sobre la supuesta inferioridad de la raza indígena y la superioridad europea fue Domingo Faustino Sarmiento. Aunque en su obra más conocida, Facundo. Civilización y barbarie, argumenta la superioridad de 
la raza europea, en el resto de su obra su pensamiento se perfilará con mayor extremismo. En Conflictos y armonías de las razas en América encontramos al Sarmiento más positivista y, a la vez, darwinista social. En este trabajo asocia cualidades humanas a razas con un resultado previsible, basándose en supuestas investigaciones seudocientíficas de antropólogos ilustres para demostrar la superioridad intelectual del europeo frente al indígena:

Las diferencias de volumen del cerebro que existen entre los individuos de una misma raza, son tanto más grandes cuanto más elevadas están en la escala de la civilización. Bajo el punto de vista intelectual, los salvajes son más o menos estúpidos, mientras que los civilizados se componen de estólidos semejantes a los salvajes, de gentes de espíritu mediocre, de hombres inteligentes y de hombres superiores. Se comprende que las razas superiores sean más diferenciadas que las inferiores, dando por sentado que el mínimum es común en todas las razas, y que el máximum, que es muy débil para los salvajes, es, al contrario, muy elevado para los civilizados. (1915: 87)

La asunción generalizada de las diferencias raciales, la ampliación del territorio nacional y la esperanza de regeneración civilizadora de la sociedad argentina impulsaron no solo las políticas de captación de inmigrantes sino también las guerras contra los indígenas por el control de las fronteras, conocidas como "Campaña del Desierto" y "Conquista del Desierto", comenzadas por Rosas y continuadas por los gobiernos de Nicolás Avellaneda y Julio Argentino Roca respectivamente. Este asumió como propio el lema de Alberdi "gobernar es poblar", instalado como paradigma de la época. Los mensajes respecto a los pueblos indígenas por parte de los gobernantes no podían ser más explícitos: "A mi juicio el mejor sistema de concluir con los indios, ya sea extinguiéndolos o arrojándolos al otro lado del río Negro, es el de la guerra ofensiva. Es necesario [...] ir directamente a buscar al indio en su guarida, para someterlo o expulsarlo" (Mensaje y Proyecto presentado por el general Roca al Congreso de la Nación el 14 de Agosto de 1878) ${ }^{1}$.

Las cifras de víctimas indígenas (entre muertos, desaparecidos y asimilados) varían entre unos estudios y otros, pero todos coinciden en que no se puede hablar de un exterminio de la población ${ }^{2}$. En su lugar, se procedió a una distribución, y poste-

\footnotetext{
${ }^{1}$ Fuente: Atlas Educativo. Programa Nacional Mapa Educativo. Ministerio de Educación de la Nación.

2 "En su estudio, Enrique Mases afirma que tras la primera etapa comandada por Roca (agosto 1878/mayo 1879), los muertos en combate fueron poco más de 1300 nativos, pero entre los 2500 indios de lanza prisioneros y reducidos voluntariamente y los 10500 no combatientes presos, eran 13000 los nativos en poder del gobierno nacional de un total de entre 20000 y 25000 sin contar a Tierra del Fuego. En cambio, para Martínez Sarasola, las bajas
} 
riormente, a la conversión en un proceso de aculturación (Nagy, 2008). Este proceso favoreció la concepción generalizada de una negación de la existencia indígena en territorio argentino, a pesar de que un estudio reciente del Conicet comprobó que el 56 por ciento de los argentinos posee $\mathrm{ADN}$ indígena ${ }^{3}$.

Las inmigraciones europeas que durante medio siglo lograron triplicar la población argentina beneficiaron esta asunción. En efecto, si en 1869 había en el país menos de dos millones de personas, de los que el diez por ciento eran extranjeros, en 1914, con cerca de ocho millones de habitantes, los foráneos ya representaban el treinta por ciento ${ }^{4}$. La posición de los gobernantes con respecto a la noción de civilización -y no olvidemos que Sarmiento fue presidente- motivaron en gran medida tanto las políticas de inmigración como las de conversión de indígenas.

El excesivo cosmopolitismo europeizante al que se vio sometido Argentina a partir de 1880 aumentó aún más las diferencias sociales, económicas, industriales y culturales entre Buenos Aires y el interior, mientras que las nuevas ideologías importadas de Europa, junto con los aportes estéticos, fueron conformando una identidad muy heterogénea que debía ser revisada en el Centenario de la Independencia.

Este proceso de revisión, no obstante, fue iniciado mucho antes. Fue Joaquín V. González el primero en refutar las conservadoras teorías sobre los indígenas que albergaban Alberdi y Sarmiento, en su obra La tradición nacional de 1887, donde, según Bazán, y "en pleno auge del positivismo... reivindicó la herencia histórica del pasado indígena y colonial" (50). Sin embargo, la aportación de González radica en la originalidad de sus postulados sobre la identidad nacional, que se basan en el rescate de la memoria de los antepasados argentinos, no solo en su vertiente hispana, sino en la precolombina, que, sin fisuras, propone como la verdadera herencia del pueblo: "Un pueblo sin tradiciones de su origen [sic] me parece que debe sufrir los mismos desconsuelos del hombre que no ha conocido sus padres, y debe envidiar á los otros que gozan en los infortunios recordando los días en que se adormecieron al rumor de los cantos maternales" (González, 1888: 37). Con González comienza la literatura regionalista en Argentina, que desde sus inicios, pretende reivindicar el peso de las regiones del interior en la nacionalidad, que hasta entonces solo se concebía desde una postura cosmopolita y porteña ${ }^{5}$. En este senti-

aborígenes entre 1878 y 1884 no superaron las 2500, y para el período 1821-1899, alcanzaron casi las 12.500, pero de una población total estimada de 200.000" (Nagy, 2008).

${ }^{3}$ Servicio de Huellas Digitales Genéticas de la Universidad de Buenos Aires (Corach, Marino y Sala 2006).

${ }^{4}$ Fuente: INDEC (Instituto Nacional de Estadística y Censos).

5 "Sobre la base de un principio de regionalización del espíritu nacional, que promueve la "conquista" por las letras de cada una de las zonas del país y proyecta el canon de una literatura auténticamente argentina como un conjunto de obras que expresen el espíritu nacional contenido en cada una de las mismas" (Chein, 2011:54); "Definir simplistamente la literatura del interior en oposición con lo porteño es limitativo, reductivo y deformante. Es 
do, la literatura nativista surgía como oposición a las nuevas tendencias extranjerizantes en un intento por la rehabilitación de una tradición nacional y en un espacio editorial menos competitivo ${ }^{6}$, pero también como un retroceso al pasado bucólico que solo el interior del país podía representar, ante los avances sociales que había traído consigo la inmigración hasta Buenos Aires.

Los escritores argentinos, pues, no cerraron los ojos ante la búsqueda de la identidad nacional frente a los cambios sociales que supusieron el rápido avance de la inmigración y de la industria. Es más, frente a las nuevas formas de criollismo literario que amenazaban con distorsionar la ya de por sí escasa alfabetización de las masas sociales, tanto Joaquín V. González como Rafael Obligado y Martiniano Leguizamón se vieron en la obligación de construir un discurso nacional capaz de atraer a todos los estratos culturales ${ }^{7}$.

La cultura popular, que se abría paso a través de folletines y de representaciones dramáticas en torno a la figura del gaucho justiciero, supuso un cambio de materia en los discursos narrativos de la cultura letrada, que los autores nacidos en provincias comenzaron a plasmar para lograr un doble objetivo: conseguir el reconocimiento literario y acceder a los gustos populares, con resultados dispares ${ }^{8}$. En el extremo de esta boga, González con Mis montañas (1893), fue capaz de registrar en diferentes capas las tradiciones y las leyendas del Noroeste argentino sin renunciar a una literatura de calidad, aunque farragosa para el lector actual. Según Romano, Mis montañas supuso un paso de la teoría (con La tradición nacional) a la

entrar en un juego perverso" (Videla de Rivero y Castellino, 2004: 34) "Se habló, en la mayor parte de los casos, de regionalismo, como tendencia que venía a sumarse, desde las provincias de tierra adentro, a la vertiente nacionalista promovida por Rojas, Gálvez y Lugones, desde la Capital, en sintonía con los sentimientos del Centenario. También de nativismo, rastreable más atrás en el tiempo; en la generación del ' 80 , en cuanto a los ancestros inmediatos (Joaquín V. González, Rafael Obligado, Martiniano Leguizamón), y en la irrupción romántica con el Echeverría de La cautiva, en la flexión histórica de la búsqueda de una conciencia y una literatura "nacionales" (Videla de Rivero y Castellino, 2004: 11).

6 "Mientras la adopción de las tendencias europeas más nuevas puede redundar en cierto prestigio en el campo local, siempre subsidiario del crédito otorgado a las letras extranjeras, la postulación de su propia producción como expresión del espíritu propio de la nación reporta un valor que aparece como insustituible y respecto del cual la prestigiosa literatura foránea no representaría una competencia" (Chein, 2010:60).

7 "En un periodo en que la noción de lo 'criollo' llega a asimilarse casi por completo a un sentido amplio de lo popular, este circuito literario masivo incorpora junto con la representación del gaucho elementos tanto de la experiencia del contingente inmigratorio como de la emergente cultura del tango. La negociación con este criollismo popular constituye la respuesta de la posición culta del nativismo a la necesidad de hacer frente a las presiones democratizadoras de estos sectores en el seno de la hegemonía oligárquica" (Chein, 2011: 30).

8 "Esta conciencia regional determinará el nacimiento de una literatura nacional que se debatirá entre lo regional y lo folklórico, entre lo popular y lo erudito" (Poderti, 2000:118). 
práctica, con la que se pretendía emular el tradicionalismo ya exitoso de Ricardo Palma en Perú, aunque sin contar con el pasado glorioso incaico (2000: 430). Con esta obra, los Andes desembarcan en la literatura argentina, hecho que no pasará desapercibido a Rafael Obligado, quien la compara a La cautiva, asignándole el calificativo de "Echeverría de los Andes". La apuesta de González, que pretende integrar a todas las regiones argentinas dentro del mismo concepto de nación, sin priorizar a ningún tipo, responde a su intento por conjugar la diversidad del país ante el empuje del cosmopolitismo y el criollismo:

La grandeza de nuestra patria tiene esta cualidad: no permitir que por un solo signo se retrate o califique toda su extensión, pues hay en ella las naturalezas más antitéticas y los climas, las vegetaciones, los hábitos y supersticiones locales más diversos...No es necesario recordar cómo desde los tiempos primitivos la región bellísima de los ríos caudalosos, de las selvas dilatadas y las cuchillas ondulantes que circundan el Paraná y el Uruguay, y á la cual conducen sus caudales repletos de limo el Paraguay, el Pilcomayo, el Bermejo, el Salado, el Carañá y otros afluentes graciosos de esta Mesopotamia feliz, fué siempre singular en sus manifestaciones sociales, y que muy poco ó nada se distingue en el sentido étnico de la ocupada por Buenos Aires que, dominadora del Río de la Plata, era, al fin, ante quien se depositaba tanta magnificencia. (Leguizamón, 1896: VIII-IX)

El regionalismo literario iniciado por González será retomado por Rojas en $E l$ país de la selva, en el que no solo se describen características geográficas, humanas e históricas a la par que se rescatan tradiciones y leyendas, sino que se aporta, además, la denuncia hacia el elemento civilizador sobre las poblaciones autóctonas, conllevando, por tanto, un tímido rasgo indigenista: "El gesto dominador de la barbarie, el ademán gallardo de los botines, habíanlos trocados por la voz débil del siervo; y por un semivestir de harapos, la desnudez plena y robusta de las edades primitivas" (1905: 55). En El país de la selva, Rojas consolida la idea de una nacionalidad heterogénea, conformada por diversas herencias dispersas en un vasto territorio del que tanto el criollo como el indígena y el inmigrante son responsables de la configuración actual de la identidad. Reacciona Rojas ante el miedo de la burguesía, que veía en la inmigración (una vez superada la asimilación de indígenas) un acicate para la ruptura del orden social vigente desde la colonia que podría hacer tambalear la argentinidad.

Rojas traza cuadros semificticios sobre la vida y las costumbres de Santiago del Estero, a los que añade la historia ensangrentada y fantasea con un porvenir poco halagüeño. Se le podría tachar a Rojas su posición despreocupada hacia la situación del indígena, pero debemos tener en cuenta que El país de la selva fue escrito cuando el escritor contaba veintitrés años. En sus posteriores obras, ya no de ficción, se acentuará su preocupación, como podemos observar en el artículo que escribió, en 1943, para la revista América Indígena, órgano de difusión del Instituto Indigenista Interamericano, creado en 1940. En dicho artículo, Ricardo Rojas exhi- 
be su conocimiento sobre la situación indígena en Argentina, su censo, su historia, su problemática y la visión del resto del país sobre esta. Propone soluciones educativas y agrarias para los indígenas y una mayor difusión de su cultura para el resto de argentinos, a quienes sigue considerando sus antepasados mestizos, y sostiene que sin ellos, Argentina habría tenido una historia bien diferente. El siguiente fragmento sintetiza el pensamiento de Rojas sobre la cuestión india:

No pedimos caridad para el indio actual; pedimos justicia en el conocimiento y en la acción. El indio fué el primer hijo del país. Los que hoy quedan sobre la tierra de sus padres, son habitantes amparados por la Constitución: hombres como nosotros, argentinos como nosotros; pero además ellos presentan, según se ha visto, un título hereditario y una posesión milenaria, que los inviste de un privilegio... Los indios argentinos que aún sobreviven, pocos o muchos, son los herederos de los que han muerto (algunos por nuestra culpa) y representan a los que murieron. Para ellos pedimos tierra; pero sabemos que el hombre autóctono vale más que esa tierra. Para ellos pedimos escuela; pero sabemos que el espíritu autóctono vale más que esa escuela... Si menospreciamos al indio comenzaremos a menospreciar lo nativo. Este "valor" de lo nativo, o sea de lo indígena, debe ser ingrediente de nuestra cultura... Sin el nuevo espíritu que preconizamos serán estériles las leyes agrarias y las escuelas indígenas que pedimos para ellos, en un sistema combinado de tierra y educación. (1943)

Ricardo Rojas contribuyó a la difusión y el reconocimiento del interior dentro de un contexto de identidad nacional en el que superaba decididamente los planteamientos sarmientinos. Tanto sus obras de reflexión, Eurindia y Blasón de plata, como de creación, El país de la selva, marcaron un punto de inflexión en la literatura regionalista. Rojas es el primer intelectual en reconocer la herencia indígena en términos genéticos, culturales y literarios, no como un lastre como lo definía Bunge, sino como un aporte meritorio al argentinismo, clave para mantener una memoria histórica que resulta fundamental para la unidad nacional. Así lo desarrolla en Blasón de plata (1912), en el capítulo titulado "Exotismo e indianismo":

Tal ha sido el origen y diferenciación de nuestra población urbana y nuestras muchedumbres rurales. Sus acuerdos, sus crisis, sus guerras, sus fluctuaciones, explican toda nuestra historia interna. Ambos constituyen el núcleo del antagonismo que Sarmiento designó después con el nombre de "Civilización y Barbarie". Pero este dilema no puede satisfacernos ya; aplicase a un período restringido de nuestra historia, y nosotros deseamos una síntesis que explique la totalidad de nuestra evolución; trasciende, además, a odio unitario, y nosotros buscamos una teoría desapasionada y de valor permanente; expresa, en fin, un juicio "europeo", puesto que transpira desdén por las cosas americanas, y nosotros queremos ver nuestro pasado como hombres de América. Bárbaros, para mí, son los "extranjeros" del latino: y no pueden serlo quienes obraban con el instinto de la patria, así fuera un instinto ciego. Por eso yo diré en adelante: "el Exotismo y el 
Indianismo" porque esta antítesis, que designa la pugna o el acuerdo entre lo importado y lo raizal, me explican la lucha del indio con el conquistador por la tierra, del criollo con el realista por la libertad, del federal con el unitario por la constitución $-\mathrm{y}$ hasta del nacionalismo con el cosmopolitismo por la autonomía espiritual. Indianismo y exotismo cifran la totalidad de nuestra historia, incluso la que no se ha realizado todavía. (1912: 163)

Este deseo de aunar las dos herencias y de asimilarlas como propias en el futuro, es ampliado en su posterior obra Eurindia (1924), donde recela de los intentos por catalogar al argentino en uno solo de sus tipos ("no queremos ni la barbarie gaucha ni la barbarie cosmopolita" (1951: 21) y aboga por "una cultura nacional como fuente de una civilización nacional; un arte que sea la expresión de ambos fenómenos" (21). La universalidad de esta obra dentro del contexto americano reporta una nueva originalidad en el sentido argentino, pues en otros países del altiplano andino, este discurso de mestizaje ya se había iniciado en los primeros años del siglo, pero es en esta misma época en la que la reivindicación del tipo transcultural se ve forjado a nivel colectivo, como es el caso del Movimiento Indigenista en Perú. Solo un año después, Vasconcelos publicará La raza cósmica, que tanto influyó en los nuevos conceptos de razas y revisionismo histórico de América Latina.

Aunque el objeto de este estudio se centra en el factor indígena en la literatura argentina, la figura del inmigrante como alteridad cobra gran importancia pues topamos ante un fenómeno sociológico sin precedentes que terminó por definir la identidad nacional, una vez finalizada la fase sorpresiva. El elemento foráneo no solo revolucionó las bases sociales, políticas y demográficas, sino también las literarias, con la entrada del modernismo. Ante ello, a partir de 1880, los escritores regionales reaccionaron al dotar a la literatura nacional con elementos propios del interior del país y ajenos a la realidad bonaerense, elementos que, a su juicio, completaron la verdadera "nacionalidad". Con el nativismo instalado en la literatura de las regiones argentinas, aparece el personaje indígena no ya con las características exóticas que le otorgase Echeverría, sino como un elemento más del paisaje argentino. Nos encontramos aún lejos de una descripción realista, pero asoman algunos atisbos de denuncia social o de reivindicación identitaria.

A ello contribuyeron ciertamente las primeras indagaciones arqueológicas y antropológicas que inició el uruguayo Lafone Quevedo y al que siguieron Adán Quiroga y Juan Ambrosetti, todos ellos rescatadores del folklore indígena. Sin embargo, y aunque su trabajo supuso un antes y un después en el estudio del pasado precolombino, es necesario señalar el carácter excluyente que otorgaron a sus investigaciones, pues no se ocuparon de la situación actual de los descendientes.

El caso de Lafone Quevedo, catamarqueño por adopción, resulta sorprendente debido a la gran cantidad de manuales, glosarios y gramáticas que escribe acerca de los idiomas mocoví, mbayá, vilela, toba, entre muchos otros, además de descrip- 
ciones de aldeas indígenas. Situación similar constituyó la de Juan Bautista Ambrosetti, considerado el "Padre de la Ciencia Folklórica", por su papel como pionero en el estudio científico antropológico y etnográfico.

Ambos arqueólogos sostienen una visión dual del indio, la del pasado y la del presente, exaltando las virtudes del primero y deshumanizando a sus herederos, muy propio en el discurso romántico-positivista:

El cerebro poco educado, infantil casi, de los indios que me ocupan, demasiado influido por la herencia de sus costumbres primitivas no podía entrar de lleno en una evolución progresiva hasta poder comprender el ideal religioso, sin tropezar en ese camino con los mil obstáculos que le oponía la fuerza regresiva del atavismo de supersticiones que pesaba sobre ellos. (Ambrosetti, 1917: 145)

Sin embargo, Adán Quiroga se acerca más a la reflexión de Ricardo Rojas, al asumir como argentina la herencia indígena y superar el binomio sarmientino. Quiroga, además de arqueólogo, cultivó la poesía y fue un notable historiador y jurista. Sus investigaciones etnográficas lo aproximaron al pueblo objeto de su estudio, como se puede leer en una de sus obras más significativas, Calchaquí:

Muchas de estas razas son las generadoras de nuestros pueblos actuales, los que llevan aún su sangre, con sus virtudes y sus vicios; triste sería la condición humana si no quisiera conocerse á sí misma en el pasado, viviendo solo para el egoísmo del presente... Pueblos bárbaros han sido los generadores de las razas que habitan la Europa actual, y en mucho tienen los europeos á los historiadores que se dedican á estudiar la vida de sus antepasados, porque desdeñarlos por el hecho de que hayan sido bárbaros ó salvages, es como despreciar á nuestros padres ó nuestros abuelos... (1897: 101)

A pesar de este avance, Quiroga insistía, como sus predecesores, en una desvirtuación de la raza indígena respecto a un pasado mucho más glorioso. Objeta a los actuales una falta de civilización y de entendimiento similar a la que hicieran los cronistas coloniales. Este fenómeno de exaltación del pasado y denostación del presente es similar al acontecido en el vecino Perú en la llamada Generación del 900. En efecto, escritores como Ventura García Calderón ${ }^{9}$ o José de la Riva-

\footnotetext{
${ }^{9}$ En 1927, García Calderón publica en Mundial el artículo "Un loable esfuerzo por el arte incaico", donde aboga por una occidentalización del indio para que pueda ser capaz de recuperar su gloria pasada. Riva Agüero, uno de los más importantes historiadores de la época incaica, se comportaba como un aristócrata y en sus últimos días estaba muy próximo a los regímenes fascistas europeos. Según Luis Valcárcel, los grupos arielistas limeños guardaban mucha distancia con los cusqueños: "A nosotros nos preocupaba enfrentar los males de una sociedad intransigentemente conservadora que dejaba de lado a la población indígena, la mayoritaria en el país. Ellos, por su parte, se sentían ajenos a ese drama y muy afectos a adoptar modelos extranjeros" (Valcárcel, 1981: 184).
} 
Agüero desasociaban incas con indígenas, a lo cual Thurner ha llamado "distopía andina" o "un aparente desencuentro entre la imaginación política criolla y las aspiraciones andinas" (Thurner, 1996: 95). En el siguiente párrafo de la misma obra de Quiroga encontramos este ejemplo contradictorio en su pensamiento:

Hasta hoy el indio de aquel tiempo, el indio inculto, existe en Tinogasta, Poman, Belen y Santa Maria; y francamente, á pesar del contacto frecuente con gente de la época, estos pobres representantes de la antigua raza no pasan de ser unos infelices, sin dotes intelectuales de ningún género, tan incapaces como sus abuelos, de hacer una construcción ó elaborar cualquiera de los antiguísimos objetos de arte que exhumamos. (181)

A continuación, refuta sus afirmaciones por la coincidencia de ideas con Lafone Quevedo, introduciendo una carta de este sobre la materia: "los calchaquinos sin duda han destruido la primitiva civilización de estos valles... falta averiguar cuál ha sido la civilización barbarizante y cuál la civilizante" (Quiroga, 1897: 76).

Mucho antes, con el cambio de siglo y la independencia, el Romanticismo se fue imponiendo como opción estética de la mano de Esteban Echeverría, que preparó el camino para el indianismo en la literatura, que retrataba personajes indios exóticos a la manera de Chateaubriand, muy alejados de la realidad. Sin embargo, existe un antecedente curioso en el teatro argentino: el drama Tupac-Amaru, de 1821, y atribuido al actor de origen peruano Luis Ambrosio Morante. En este se realiza una defensa del indígena peruano, pero por su filiación genérica no será analizado aquí.

Habrá que saltar hasta la segunda mitad del siglo XIX para encontrar las primeras manifestaciones literarias de defensa hacia el indígena argentino, y muy probablemente la segunda narración preindigenista en todo el continente americano (después de El Padre Horán, de 1848). Su autora, Juana Manuela Gorriti, nacida en Salta en 1818, fue una de las figuras más extraordinarias de la literatura argentina del XIX. Su obra, La Quena, publicada en 1845, ha sido considerada como la primera novela argentina ${ }^{10}$, adelantándose a Amalia, de José Mármol, en seis años.

Gorriti, hija de un héroe de la Independencia, estuvo en contacto con el mundo indígena durante toda su vida. Además de haber nacido en Salta, durante la dictadura de Rosas se instaló primero en Sucre y finalmente en Lima, donde desarrolló gran parte de su actividad intelectual reconocida entre sus contemporáneos por su activismo literario y político.

Amiga de Ricardo Palma y Clorinda Matto de Turner, Juana Manuela fue la anfitriona de un prestigioso salón literario en la década de 1870 y dirigió la revista $L a$

10 “En 1848, Juana Manuela Gorriti publica una novela de corte histórico, titulada La Quena. Este hecho, sin duda, sitúa a la escritora en el papel que la historia de la literatura debe reconocerle: el de ser la primera novelista argentina" (Poderti, 2000:92). 
Alborada del Plata (1877-1879), con interesantes artículos periodísticos femeninos. Su producción literaria se centraba en temática indígena, coincidiendo con el incaísmo ${ }^{11}$ prevaleciente en la región que exaltaba las virtudes de la sociedad incaica sin tener en cuenta a sus descendientes. Pero entre su ingente obra, un relato, "Si haces mal no esperes bien", inaugura el indigenismo en la literatura (González y Enrique, 2008: 144), mientras que Efraín Kristal lo incluye dentro de la nómina de obras indigenistas, y sitúa a El padre Horán, del peruano Narciso Aréstegui como la precursora.

El cuento, dividido en cuatro capítulos, fue publicado en 1861 en La Revista de Lima y luego en La Revista de Buenos Aires. En él se retratan las consecuencias de la opresión hacia el sector indígena de la población, con la narración de en un drama romántico de nefastas consecuencias. Gorriti focaliza el abuso de una sociedad feudal corrupta en la "trinidad embrutecedora" que González Prada denunció treinta años después: el cura, el juez y el soldado, y lejos de centrar su historia en la elitista descendencia inca, lo hace con los anónimos indígenas sometidos durante siglos por el europeo y el criollo, y a los que cede su voz para denunciar la tiranía y el abuso:

Dicen que nuestros padres, poderosos en otro tiempo, reinaron en este suelo que nosotros pagamos tan caro; y que los blancos viniendo de una tierra lejana, les robaron su oro y su poder. No sé si eso es cierto, pero ahora que somos pobres, ahora que nada pueden ya quitarnos, nos roban nuestros hijos para hacerlos esclavos en sus ciudades. (1865: 179)

Aunque el discurso de Gorriti no es reivindicativo, es necesario tener en cuenta la similitud entre este relato y Aves sin nido, de Clorinda Matto de Turner, ampliamente difundido como la primera manifestación literaria indigenista y publicado en 1889 , casi treinta años después que la argentina ${ }^{12}$. Su clasificación dentro del espectro indigenista se fundamenta por la denuncia, característica que también comparte el cuento de Gorriti.

11 “El incaísmo puede caracterizarse como la representación de la conquista generada por el grupo criollo, que asume como tarea la construcción de la nación. Esta literatura toma como personajes a los soberanos incas y concibe a la colonia como un período nefasto, contrapuesto al orden precolonial; el tópico de la venganza posibilita la relación incas-patriotas. El incaísmo sólo procesa el pasado, ignorando el presente de la mayoritaria población indígena, lo que lo diferencia del indigenismo, en tanto éste ya se propone reivindicar los derechos del indígena" (Royo, 1999: 35).

12 "Debe señalarse que el cuento de esta autora tiene la misma estructura básica de Aves sin nido escrita unos treinta años después por Clorinda Matto de Turner. Este hecho no ha sido tomado en cuenta por los críticos de la literatura indigenista, ya que las obras de J. M. Gorriti han sido injustamente ignoradas" (Kristal, 1991:31). 
Si bien la reivindicación literaria plenamente indigenista se produjo a partir de los años 20 en el territorio argentino de la mano de escritores como Fausto Burgos, Alcides Greca o Pablo Rojas Paz, autores cuya obra ha sido olvidada por la crítica indigenista peruana y marginada por la crítica literaria argentina, tanto las tendencias herderianas regionalistas como la aportación denunciatoria de Juana Manuela Gorriti prepararon el campo literario para el surgimiento de una narrativa que denunciaba el olvido, el sometimiento y la humillación de miles de indígenas argentinos.

\section{BIBLIOGRAFÍA}

ALBERDI, Juan Bautista, y Joaquín GONZÁLEZ.

1920 Bases y comentarios de la Constitución argentina. Buenos Aires: Librería "La Facultad" de Juan Roldán.

AMBRoseTTI, Juan B. Debenedetti Salvador.

1917 Supersticiones y leyendas: región misionera-valles calchaquies, las Pampas. Buenos Aires: La Cultura argentina.

CORACH, Daniel, Miguel MARINO y Andrea SALA.

2006 "Relevant Genetic Contribution of Amerindian to the Extant Population of Argentina". International Congress Series, n. 1288.1, 2006, pp. 397-399.

CHEIN, Diego J.

2010 "Escritores y Estado en el Centenario: apogeo y dispersión de la literatura nativista argentina". Revista Chilena De Literatura, n. 77, 2010, pp. 51-73.

2011 "Argentinos de profesión. El debate nativista en torno a la poesía gauchesca". Revista de Crítica Literaria Latinoamericana, n. 37.74, 2011, pp. 25-48.

ECHEVERRÍA, Esteban.

1916 La cautiva. La guitarra. Elvira. Buenos Aires: Vaccaro.

GONZÁLEZ ECHEVARRÍA, Roberto y Enrique PUPO-WALKER.

2008 The Cambridge History of Latin American Literature. Vol. 2, Cambridge, Cambridge University Press.

GONZÁLEZ, Joaquín Víctor.

1888 La tradicion nacional. Buenos Aires: Lajouane.

GORRITI, Juana Manuela.

1865 Sueños y realidades. Obras completas de la señora doña Juana Manuela Gorriti. Buenos Aires, Impr. de Mayo de C. Casavalle.

KRISTAL, Efraín.

1991 Una visión urbana de los Andes: génesis y desarrollo del indigenismo en el Perú: 1848-1930. Lima: Instituto de Apoyo Agrario.

LEGUIZAMÓN, Martiniano.

1896 Recuerdos de la tierra. Buenos Aires: Félix Lajouane. 
Ministerio de Educación de la Nación.

2015 Atlas Educativo. Programa Nacional Mapa Educativo. Disponible en http://www.mapaeducativo.edu.ar/atlas/. Fecha de consulta: 13 de octubre de 2015.

NAGY, Mariano.

2008 "Los pueblos originarios y las consecuencias de la Conquista del desierto (1878-1885). Perspectivas desde un estado de la cuestión". Introducción a los Derechos Humanos. Buenos Aires: Oficina de Publicaciones de la Facultad de Filosofía y Letras.

PODERTI, Alicia.

2000 La narrativa del noroeste argentino: historia socio-cultural. Salta: Milor.

QUIROGA, Adán.

1897 Calchaquí. Tucumán: Impr. Española.

ROJAS, Ricardo.

1905 El país de la selva. Paris: Garnier Hermanos.

1912 Blasón de Plata: meditaciones y evocaciones de Ricardo Rojas sobre el abolengo de los argentinos. Buenos Aires: M. García.

1943 "El problema indígena en Argentina". América Indígena, vol. 3, 1943, pp. 105-114.

1951 Eurindia; ensayo de estética sobre las culturas americanas. Buenos Aires: Losada.

ROMANO, Eduardo.

2001 "Origen, trayectoria y crisis de la novela regionalista argentina". En INTI, vol. 52-53, 2001, pp. 429-460.

RoYo, Amelia.

1999 Juanamanuela, mucho papel: algunas lecturas criticas de textos de Juana Manuela Gorriti. Salta: Ediciones del Robledal.

SARMIENTO, Domingo Faustino y José INGENIEROS.

1915 Conflicto y armonías de las razas en América. Buenos Aires: La Cultura argentina.

THURNER, Mark.

1996 "Republicanos y la Comunidad de Peruanos: Comunidades políticas inimaginadas en el Perú postcolonial”. En Histórica, vol. XX, 1996, pp. 93-130.

VALCÁRCEL, Luis E.

1981 Memorias. Lima: Instituto de Estudios Peruanos.

VIDELA DE RiVERO, Gloria y Marta Elena CASTELlino.

2004 Literatura de las regiones argentinas. Mendoza: Universidad Nacional de Cuyo, Facultad de Filosofía y Letras, Centro de Estudios de Literatura de Mendoza. 